Available online at GSC Online Press Directory

GSC Biological and Pharmaceutical Sciences

e-ISSN: 2581-3250, CODEN (USA): GBPSC2

Journal homepage: https://www.gsconlinepress.com/journals/gscbps

(RESEARCH ARTICLE)|

\title{
Effect of medications misused for body weight gain on sodium and potassium concentration of female rabbits
}

\author{
Adam Saba Siddig1, Ahmed Adam Ismail 2, ${ }^{*}$ and Babeker Awad Mohammed ${ }^{2}$ \\ ${ }^{1}$ Faculty of Education, Department of Chemistry, University of Kordofan, Elobeid, Sudan. \\ ${ }^{2}$ Department of Food Science and Technology, Faculty of Natural Resources and Environmental Studies, University of \\ Kordofan, Elobeid, Sudan, P.O. Box .160.
}

Publication history: Received on 25 October 2017; revised on 15 November 2017; accepted on 09 January 2018

https://doi.org/10.30574/gscbps.2018.2.1.0054

\begin{abstract}
The objective of this study was to determine the effect of some drugs on body weight, potassium and sodium concentration of female rabbits. A randomized complete block design with three replicates was used, the treatments consisted of 3 drugs of dexamethasone, cyperoheptadine and the combination of dexamethasone and cyperoheptadine administered orally with doses of $0.9 \mathrm{mg} / \mathrm{kg}$ of body weight with drugs two times a day for 45 days. Body weight and the concentration of sodium and potassium were measured. The results showed that body weight and the concentration of sodium and potassium significantly affected with treatments. The cyperoheptadine of this drugs increased body weight from ( 910 at zero time to $1693 \mathrm{~g}$ at the end of experimental period), where the increments found to be out of the normal range (16 g). It was found that potassium concentration decreased with time and the final values were (2.20 $\mathrm{mg} / \mathrm{dl}),(2.60 \mathrm{mg} / \mathrm{dl}),(3.20 \mathrm{mg} / \mathrm{dl})$ for dexamethasone, the combination and cyperoheptadine, respectively. No significant differences between these values found and they were below the normal range of potassium concentration (4.0-6.5 mg/dl). According to the results found the study concluded that cyperoheptadine and the combination increased body weight. All drugs decreased potassium concentration. Physician and pharmacist should be consultant before using these drugs to avoid the adverse effects is needed as recommended point of view, effects of drugs on serum total cholesterol, triglyceride, high-density lipoprotein, low density lipoprotein and very low density lipoprotein are also recommended for future work.
\end{abstract}

Keywords: Administered drugs; Female rabbits; Sodium and potassium concentration; Body weight

\section{Introduction}

The causes of weight gain were not known exactly due to some interaction between drugs and medications roles in this position. Because some medications can increase appetite, by causing fluid retention, or slowly lead to weight gain during a period of applications or due to fatigue and lower activity that cause weight gain. Some difficulties were found in order to distinguish between weight gain from a drug and weight gain from other factors like lower activity and due to the consumption plenty of foods or diet, some harmfulness can be resulted or may increase the chance for high cholesterol, hypertension (high blood pressure), and type 2 diabetes [1]. One of the most drugs misused by Sudanese women for body weight gain is dexamethasone (locally knows as Alnagma) are tablets for oral administration has many uses in the treatment of cancer. It is classified as a glucocorticosteroid [2].

Some side effects are common for patients whom administered dexamethasone enhanced the levels of appetite, irritability, difficulty sleeping, swelling in ankles and feet (fluid retention) heartburn, muscle weakness, impaired wound

\footnotetext{
${ }^{*}$ Corresponding author

E-mail address: adamalgnana62@ yahoo.com
}

Copyright (C) 2018 Author(s) retain the copyright of this article. This article is published under the terms of the Creative Commons Attribution Liscense 4.0. 
healing and increased blood sugar levels and may others side effects with different level of occurrences [1]. Cyperoheptadinelocally knows as peiractin, cyperoheptadine is an antihistaminic and antiserotonergic agent [2].

People believed dexamethasone it played a role in causing malignances, it may given at risk at delivering of premature in order to cause maturation of fetus lungs [3-4]; After a single $4 \mathrm{mg}$ oral dose of cyperoheptadineHCl, 2 to $20 \%$ of the radioactivity was excreted in the stools of those patients. While there were no changes appeared of the drug in about $34 \%$ of the stool radioactivity, corresponding to less than $5.7 \%$ of the dose. There were almost $40 \%$ of the administered radioactivity was excreted in the urine. The urine of patients on chronic 12 to $20 \mathrm{mg}$ daily doses was free from cyperoheptadine administered in above mention dose. The principle metabolite found in human urine has been identified as a quaternary ammonium glucuronide conjugate of cyperoheptadine. Elimination is diminished in renal insufficiency [5], so the main objective of this study to know the effect of dexamethasone and cyperoheptadine drugs abused by Sudanese women for weight misused in female rabbits and their affects in body weight and also their role on the concentration of sodium and potassium.

\section{Material and methods}

\subsection{Drugs}

Dexamethasone and cyperoheptadine tablets were procured from super market in Elobeid, North Kordofan State, Sudan.

Each tablet was crashed ( $0.9 \mathrm{mg}$ ) into powder and then mixed with $1 \mathrm{ml}$ of distilled water and kept as stock drug. Before use the stock suspension was homogenized sonicator and diluted to obtain appropriate doses concentration (100 ml).

\subsection{Treatment}

Each group was treated with the prepared drugs as follows:

First group: No treatment (control).

Second group: administration dexamethasone orally $(1.8 \mathrm{mg} / \mathrm{kg}$ body weight) daily.

Third group: cyperoheptadine $(1.8 \mathrm{mg} / \mathrm{kg}$ body weight) daily.

Fourth group: combined suspension $(1.8 \mathrm{mg} / \mathrm{kg})$ daily.

\subsection{Experimental animals}

Sixteen female rabbits from local markets of Elnuhod weighted 700-2000 grams were divided equally and randomly into four groups, Each group was kept in one cage, the animals were provided with composed of green carrot (Caucus carrot $)$ as well as tap water and maintained in air-conditioned quarters $\left(24^{\circ} \mathrm{C}\right)$ under standard husbandry conditions with alternate 12 hours light /dark period tell the end of experiment period ( 45 days).

\subsection{Blood samples collection}

Blood samples collected directly from the heart (cardiac puncture) in the first day and then every 15 days. Blood was collected in plastic tubes without anticoagulant and then refrigerated for 12 hour as maximum pending the analysis. Blood samples were centrifuged (5000 rpm) for 15 minutes to separate serum, and then used for determination of sodium and potassium contents.

\subsection{Measurements of body weight}

Body weight was measured by balance of $20 \mathrm{~kg}$ capacity. Animals were weighed every 7 days till the end of the experimental period.

\subsection{Determination of sodium and potassium concentration}

Sodium and potassium were determined by International standard (lithium chloride) used as diluents for estimation of sodium and potassium, then $5 \mathrm{ml}$, was added in tubes standard and blank $50 \mu \mathrm{L}$ of sample standard added to the specific tube, used for adjustment of zero and standard for adjustment of sodium $140 \mathrm{mmol} / \mathrm{L}$, and potassium $40 \mathrm{mmol} / \mathrm{L}$ then samples were measured directly on the flame photometer (Jenway) [6]. 


\subsection{Statistical analysis}

In order to compare the effects of the treatments on the body weight and sodium and potassium contents of rabbits, data were analyzed for ANOVA using complete randomized design (CRD) with help of computer program Statistical Packages for Social Science (SPSS V.19). Mean separation was done using the Least significant differences (LSD), as described by Sendecor, and Cochran [7], then the results were tabulated (means \pm SD).

\section{Results and discussion}

\subsection{Effects of administered drugs on the body weight (g) of female rabbits}

As shown in table 1, with respect to comparison between groups, after 7 days of application of the treatments, no significant $(\mathrm{p} \leq 0.05)$ differences were found in weight between dexamethasone, cyperoheptadine, the combination of dexamethasone with cyperoheptadine and the control. After 15 days of the trial, no significant $(p \leq 0.05)$ differences in weight between dexamethasone, cyperoheptadine and the combination of dexamethasone + cyperoheptadine and no significant $(\mathrm{p} \leq 0.05)$ difference was found between cyperoheptadine, the combination of dexamethasone + cyperoheptadine and the control, but dexamethasone demonstrated a significant $(\mathrm{p} \leq 0.05)$ lower weight than that reported for the control (284.75 g), cyperoheptadine and the combination of dexamethasone with cyperoheptadine $(226.05 \mathrm{~g})$.

After 21 days, no significant ( $\mathrm{p} \leq 0.05$ ) difference was observed in weight between cyperoheptadine and the combination of dexamethasone with cyperoheptadine treatment group and the control group. However, dexamethasone showed a lower weight than that showed by cyperoheptadine, the combination of dexamethasone + cyperoheptadine and the control by $435 \mathrm{~g}, 373 \mathrm{~g}$ and $393 \mathrm{~g}$ respectively and these differences were found to be significant $(\mathrm{p} \leq 0.05)$.

After 28 days, there was no significant $(\mathrm{p} \leq 0.05)$ difference in weight between cyperoheptadine and the combination of dexamethasone with cyperoheptadine and between these treatments and the control, while dexamethasone showed a lower weight than that showed by cyperoheptadine, the combination of dexamethasone with cyperoheptadine and the control by $704.75 \mathrm{~g}, 543.25 \mathrm{~g}$ and $525.25 \mathrm{~g}$ respectively and these differences were found to be significant at ( $\mathrm{p} \leq 0.05$ ).

After 35 days of experimental period no significant $(\mathrm{p} \leq 0.05)$ difference in weight between the combination of dexamethasone with cyperoheptadine and the control, while dexamethasone showed a lower weight than that reported by cyperoheptadine, the combination of dexamethasone with cyperoheptadine and the control by $972.5 \mathrm{~g}, 706.0 \mathrm{~g}$ and 602.3grespectively and these differences were significant at 0.05 level of significance. The weight demonstrated by cyperoheptadine was noticed to be higher than that recorded by the combination of dexamethasone with cyperoheptadine by (266.5 g) and higher than that recorded by control by $370.0 \mathrm{~g}$ and these differences were significant $(\mathrm{p} \leq 0.05)$.

After 42 days, it was found that the differences between all treatments were significant ( $\mathrm{p} \leq 0.05)$, dexamethasone recorded the lowest weight and the differences in weight values between dexamethasone and cyperoheptadine, the combination of dexamethasone with cyperoheptadine and the control were $1240.8 \mathrm{~g}, 819.0 \mathrm{~g}$ and $614.3 \mathrm{~g}$, respectively. The highest weight values were demonstrated in sequence by cyperoheptadine and the combination of dexamethasone with cyperoheptadine.

With respect to comparison within the same group due to times, the control showed no significant differences in weight gain throughout time of the experiment and the increments in weight were almost around the normal value (16 g). With regard to dexamethasone, there was reduction in body weight as the time proceed which agreed with Rashad and Ala AL-Deen [8], and the lowest body weight was recorded at 42 days (the end of the trial) and it was(453.0 g). No significant differences in weight reduction values between 28 days, 35 days and 42 days, at 21 days the body weight was664.0 $\mathrm{g}$ where there was significant differences between weight at 42 days and weights during time lag from $0-21$ days at 0.05 level. Dexamethasone found to cause reduction in body weight by $114 \mathrm{~g}, 65 \mathrm{~g}$ and $127 \mathrm{~g}$ during period intervals 7-15 days, 21-28 days and 35-42 days, respectively.

In case of cyperoheptadine, the body weight was increased as time passes, the highest weight was $1693.8 \mathrm{~g}$ and it was recorded at 42 days, the nearest value was $1438.5 \mathrm{~g}$ and it was obtained at 35 days and the difference of $255.3 \mathrm{~g}$ between the two values found to be significant at $(\mathrm{p} \leq 0.05)$ levels. During the period $0-7$ days, the increment in weight was (18.25 g) which can be considered around the normal weight gain (16 g) while during the period intervals between 7 days to 42 days the increment in body weight ranging from $73.55 \mathrm{~g}$ to $255.3 \mathrm{~g}$ which is much higher than accepted normal limit. 
Considering the combination of dexamethasone with cyperoheptadine, the body weight increased with time. There was no significant differences in weight between 28 days, 35 days and 42 days, the highest weight value was $1272.0 \mathrm{~g}$ and was recorded at 42 days, while at 21 days the weight was $1037.0 \mathrm{~g}$, the difference between two weight values was significant at 0.05 level, therefore, the differences between weight at 42 days and weight during period from 0-15 days were significant at (0.05) level. During the period 0-7 days, the increment in weight was $8.25 \mathrm{~g}$ that can be considered around the normal weight gain (16 g) while during the period intervals between 7 days to 42 days the increment in body weight ranging from $35.2 \mathrm{~g}$ to $100.9 \mathrm{~g}$ which is much higher than accepted normal limit of weight gain.

Table 1 Effects of administered drugs on the body weight of female rabbits

\begin{tabular}{lccccccc}
\hline \multirow{2}{*}{ Treatments } & \multicolumn{7}{c}{ Periods (days) } \\
\cline { 2 - 8 } & Zero time & $\mathbf{7}$ & $\mathbf{1 5}$ & $\mathbf{2 1}$ & $\mathbf{2 8}$ & $\mathbf{3 5}$ & $\mathbf{4 2}$ \\
\hline Control & $1050.0^{\mathrm{Aa}}$ & $1061.8^{\mathrm{Aa}}$ & $1060.5^{\mathrm{Aa}}$ & $1057.0^{\mathrm{Aa}}$ & $1062.0^{\mathrm{Aa}}$ & $1068.3^{\mathrm{Ba}}$ & $1067.3^{\mathrm{Ca}}$ \\
& \pm 27.08 & \pm 28.15 & \pm 41.16 & \pm 25.85 & \pm 24.89 & \pm 31.38 & \pm 26.84 \\
Dexamethasone & $880.00^{\mathrm{Aa}}$ & $859.75^{\mathrm{Aa}}$ & $775.75^{\mathrm{bab}}$ & $664.00^{\mathrm{Bbc}}$ & $546.75^{\mathrm{Bcd}}$ & $466.00^{\mathrm{Cd}}$ & $453.00^{\mathrm{Dd}}$ \\
& \pm 141.19 & \pm 134.41 & $\pm 105.00)$ & \pm 72.99 & \pm 50.72 & \pm 31.38 & \pm 27.83 \\
Cyperoheptadine & $910.00^{\mathrm{Ad}}$ & $928.25^{\mathrm{Ad}}$ & $1001.8^{\mathrm{Abd}}$ & $1099.0^{\mathrm{Acd}}$ & $1251.5^{\mathrm{Abc}}$ & $1438.5^{\mathrm{Ab}}$ & $1693.8^{\mathrm{Aa}}$ \\
& \pm 189.21 & \pm 187.90 & \pm 178.93 & \pm 161.42 & \pm 141.90 & \pm 134.44 & \pm 134.40 \\
Dexa and Cyper & $952.50^{\mathrm{Ac}}$ & $960.75^{\mathrm{Ac}}$ & $1001.8^{\mathrm{Abbc}}$ & $1037.0^{\mathrm{Abc}}$ & $1090.0^{\mathrm{Aabc}}$ & $1172.0^{\mathrm{Bab}}$ & $1272.0^{\mathrm{Ba}}$ \\
& \pm 134.44 & \pm 133.24 & \pm 133.2 & \pm 130.99 & \pm 131.19 & \pm 131.19 & \pm 130.25 \\
\hline
\end{tabular}

*Each value is an average of three replicates and value is average \pm standard deviation.

*Values in column share the same superscript capital letters show no significant difference between groups at 0.05 levels

*Values in Rows share the same superscript small letters show no significant difference within groups at 0.05 levels.

\subsection{Effect of administered drugs on sodium concentration of female rabbits}

There were no significant ( $\mathrm{p} \leq 0.05$ ) differences between treatments at first days, 15 days and 30 days in their effects on Na concentration (table 2), at 45 days, the combination of dexamethasone with cyperoheptadineshowed significant ( $\mathrm{p} \leq$ 0.05) differences as compared with the control, while no significant ( $\leq \leq 0.05$ ) differences as compared with dexamethasone and cyperoheptadine. With respect to comparison within the group at different periods of time, no significant differences in $\mathrm{Na}$ concentration were recorded in case of the control from first days up to 45 days. In case of dexamethasone, there was significant $(\mathrm{p} \leq 0.05)$ difference was found in sodium concentration between first days and 45 days and between 15 days and 45days. In case of cyperoheptadine and the combination of dexamethasone with cyperoheptadine, 45 days period significant ( $\mathrm{p} \leq 0.05$ ) differences as compared with first days, 15 days and 30 days. It was found that Na concentration decreased with time and the lowest value was $121.67 \mathrm{mmol} / \mathrm{L}$, which shown by the combination of dexamethasone with cyperoheptadine followed by cyperoheptadine (128.67mmol/l) and dexamethasone $(132.25 \mathrm{mmol} / \mathrm{l})$. It can be concluded that the application of drugs reduced Na concentration in the body but the level was kept within the normal range (130-155 mmol/l) during the trial period thatin agreement of the findings elaborated by Amar et al. [9] for wistar rats.

Table 2 Effect of administered drugs on sodium concentration of female rabbits

\begin{tabular}{lcccc}
\hline & \multicolumn{4}{c}{ Periods (days) } \\
\cline { 2 - 5 } Treatments & Zero time & $\mathbf{1 5}$ & $\mathbf{3 0}$ & $\mathbf{4 5}$ \\
\hline Control & $(148.25)^{\mathrm{Aa}} \pm 5.68$ & $(146.50)^{\mathrm{Aa}} \pm 3.32$ & $(146.50)^{\mathrm{Aa}} \pm 6.18$ & $(144.50)^{\mathrm{Aa} \pm 6.40}$ \\
Dexamethasone & $(151.50)^{\mathrm{Aa}} \pm 4.73$ & $(146.00)^{\mathrm{Aab}} \pm 4.55$ & $(146.00)^{\mathrm{Abc} \pm 3.95}$ & $(132.25)^{\mathrm{Abc}} \pm 7.97$ \\
Cyperoheptadine & $(148.33)^{\mathrm{Aa} \pm 5.69}$ & $(145.00)^{\mathrm{Aab}} \pm 5.29$ & $(145.00)^{\mathrm{Ab} \pm 7.81}$ & $(128.67)^{\mathrm{Abc}} \pm 4.93$ \\
Dexa and Cyper & $(150.67)^{\mathrm{Aa} \pm 10.12}$ & $(140.00)^{\mathrm{Aab}} \pm 10.12$ & $(140.00)^{\mathrm{Aa} \pm 15.13}$ & $(121.67)^{\mathrm{Bb}} \pm 13.79$ \\
\hline
\end{tabular}

*Each value is an average of three replicates. Value is average \pm standard deviation.

*Values in column share the same superscript capital letters show no significant difference between groups at 0.05 levels. *Values in Rows share the same superscript small letters show no significant difference within groups at 0.05 levels. 


\subsection{Effect of administered drugs on potassium concentration of female rabbits}

There were no significant ( $\mathrm{p} \leq 0.05$ ) differences between treatments at first days, 15 days, 30 days and 45 days in their potassium concentration (table3). With regard to comparison within the group at different periods of time, no significant differences in potassium concentration were found in the control from first days to 45 days. In case of dexamethasone, there was significant $(\mathrm{p} \leq 0.05)$ difference was found in potassium after 45 days as compared with first days, 15 days and 30 days. Cyperoheptadine and the combination of dexamethasone with cyperoheptadine showed no significant differences ( $\mathrm{p} \leq 0.05)$ between 15 days, 30 days and 45 days. Minor decreased in potassium concentration were obtained in progress of the experiment, the values were $2.20 \mathrm{mg} / \mathrm{dl}, 2.60 \mathrm{mg} / \mathrm{dl}, 3.20 \mathrm{mg} / \mathrm{dl}$ for dexamethasone, the combination of dexamethasone with cyperoheptadine and cyperoheptadine, respectively, those values found to be below the normal range of potassium concentration $(4.0-6.5 \mathrm{mg} / \mathrm{dl})$ [9].

Table 3 Effect of administered drugs on potassium concentration of female rabbits

\begin{tabular}{lcccc}
\hline & \multicolumn{4}{c}{ Periods (days) } \\
\cline { 2 - 5 } Treatments & Zero time & $\mathbf{1 5}$ & $\mathbf{3 0}$ & $\mathbf{4 5}$ \\
\hline Control & $(4.80)^{\mathrm{Aa}} \pm 0.25$ & $(4.40)^{\mathrm{Aa}} \pm 0.63$ & $(4.18)^{\mathrm{Aa}} \pm 0.67$ & $(4.13)^{\mathrm{Aa}} \pm 0.67$ \\
Dexamethasone & $(4.45)^{\mathrm{Aa}} \pm 0.42$ & $(4.00)^{\mathrm{Aa}} \pm 0.36$ & $(3.30)^{\mathrm{Ab}} \pm 0.41$ & $(2.20)^{\mathrm{Ac}} \pm 0.22$ \\
Cyperoheptadine & $(4.35)^{\mathrm{Aa}} \pm 0.35$ & $(3.65)^{\mathrm{Aab}} \pm 0.48$ & $(3.33)^{\mathrm{Aab}} \pm 0.47$ & $(3.20)^{\mathrm{Ab}} \pm 1.33$ \\
Dexa and Cyper & $(4.90)^{\mathrm{Aa}} \pm 1.33$ & $(3.90)^{\mathrm{Aab}} \pm 0.14$ & $(3.35)^{\mathrm{Ab}} \pm 0.64$ & $(2.60)^{\mathrm{Ab}} \pm 0.57$ \\
\hline
\end{tabular}

*Each value is an average of three replicates. The value is average \pm standard deviation.

*Values in column share the same superscript capital letters show no significant difference between groups at 0.05 levels.

*Values in Rows share the same superscript small letters show no significant difference within groups at 0.05 levels.

\section{Conclusion}

Dexamethasone drug caused reduction in body weight, while cyperoheptadine and the combination of dexamethasone and cyperoheptadine caused increasing in female rabbit's body weight. The application of drugs reduced sodium concentration in the blood but the level was kept within the normal range during the trial period.Potassium concentration was decreased by dexamethasone, the combination of dexamethasone with cyperoheptadine and cyperoheptadine effects on potassium concentration below the normal range.

Recommendations: More elaborated work concerning weight-gaining drugs should be carried-out considering longer experimental period as well as larger sample size of different laboratory animals. Effects of drugs on serum total cholesterol, triglyceride, high-density lipoprotein, low density lipoprotein and very low density lipoprotein.

\section{Compliance with ethical standards}

\section{Acknowledgments}

The authors appreciated the help given by the staff of central veterinary laboratory, Elobeid, Department of chemistry faculty of education; the dean faculty of neural resources and environmental studies is also appreciated.

\section{Disclosure of conflict of interest}

The authors declared that no conflicts of interest for this article.

\section{Statement of ethical approval}

Ethical permission was taken from the wildlife authority department action no (52/5/A/6M). 


\section{References}

[1] Pagana KD and Pagana TJ. (2010). Mosby's manual of diagnostic and laboratory tests, $4^{\text {th }}$ ed. St. Louis: Mosby Elsevier.

[2] De Wasch K, De Brabander HF, Van De Wiele M, VarcammenJ and Courtheyn D. (2001). Differentiation between dexamethasone and betamethasone in a mature using multiple mass spectrometry. Journal of Chromatography A, 926, $79-86$.

[3] Siddigui E and Qazi GI. (2012).Role of dexamethasone in meningitis. In: Meningitis, Wireko-Brobby G. (Ed.) Intech, USA.

[4] Bloom SL, Sheffield JS, McIntire DD and Leveno KJ. (2001). Antenatal dexamethasone and decreased birth weight. Obstetrics and Gynecology, 97, 485-490.

[5] Welsh AL and Ede M. (2013). Studies of cyperoheptadine combined with dexamethasone. Journal of Clinical Pharmacology, 2, 223 - 231.

[6] Murray RK, Granner DK, Mayes PA and Rodwell VW. (2006). Harper lustrated Biochemistry. 27th ed., MC GrawHill, New York, 489-504.

[7] Sendecor GW and Cochran WC. (1989). Statistical Method, $8^{\text {th }}$ Ed. Iowa State University press, Ames, Iowa.

[8] Rashad FG and Ala AL-deen HJ. (2013). Effects of dexamethasone, estrogen administration on leptin, thyroid, reproductive hormone concentration and lipid profile of female rabbits serum. Basrah Journal of Veterinary Research. 12(1), 41-53.

[9] Amar MI, Shama IA, Enaia AA, Hind AEO and Hager AM. (2013). Effects of various levels of oral doses dexamethasone (Al-nagma) abused as cosmetic by Sudanese women on Wistar rats. Journal of Medical Sciences, $13(6), 432$.

\section{How to cite this article}

Adam SS, Ahmed AI and Babeker AM. (2018). Effect of medications misused for body weight gain on sodium and potassium concentration of female rabbits. GSC Biological and Pharmaceutical Sciences, 2(1), 32-37. 